\title{
Morphological characterisation and glycaemic responses of cake developed from carrot and concentrated Nypa fruticans sap
}

\author{
${ }^{1}$ Tai, Y.Y., ${ }^{2}$ Tengku Ismail, T.A. and ${ }^{1, *}$ Wan Rosli, W.I. \\ ${ }^{1}$ School of Health Sciences, Universiti Sains Malaysia Health Campus, 16150 Kubang Kerian Kelantan, \\ Malaysia \\ ${ }^{2}$ School of Medical Sciences, Universiti Sains Malaysia Health Campus, 16150 Kubang Kerian, Kelantan, \\ Malaysia
}

\begin{abstract}
Article history:
Received: 3 November 2020

Received in revised form: 8

December 2020

Accepted: 5 February 2021

Available Online: 13 June

2021
\end{abstract}

\section{Keywords:}

Bakery product,

Glycaemic index,

Microstructure

characteristics,

Natural sugar,

Nypa fruticans sap

DOI:

https://doi.org/10.26656/fr.2017.5(3).628

\begin{abstract}
Glycaemic index is the classification of carbohydrate foods based on their blood glucose responses. In the market, most bakery products contain a high amount of sugar and could directly increase the glycaemic index of the food. Using carrot cake as a bakery product model, the sugar in the cake was replaced with sap produced by Nypa fruticans palm. After undergoing dehydration at $62^{\circ} \mathrm{C}$ to preserve the palm sap, it was directly incorporated into carrot cakes to replace the table sugar at $0 \%$ (control) and $20 \%$ level. Both the products were then analysed using scanning electron microscopy to observe their microscopic characteristics. The findings suggested that there was a denser, more compact and lesser number of air cells structure in the carrot cake incorporated with $20 \%$ concentrated $N$. fruticans sap compared to the cake without the addition of concentrated $N$. fruticans sap. The carrot cake incorporated with $20 \%$ concentrated $N$. fruticans sap was found to have a glycaemic index value of 50 which was significantly lower than the control carrot cake with a glycaemic index value of 55. Although the incorporation of concentrated $N$. fruticans sap did not lower the postprandial peak glucose responses of carrot cake, it helped in lowering the glycaemic index value of carrot cake.
\end{abstract}

\section{Introduction}

The nipa palm (Nypa fruticans) is a high sugaryielding mangrove palm tree that produces palm sap from the cut stalks of infructescence after the removal of the floral or fruit heads (Fong, 1992; Hamilton and Murphy 1988; Päiväke, 1996). Nypa fruticans sap (NFS) composed mainly of sucrose, glucose and fructose and it is also an abundant source of inorganic minerals, amino acids and vitamins (Aimi et al., 2013; Nguyen et al., 2016). Due to this high sugar content, the NFS has been utilised as a material of treacle, amorphous and for producing vinegar alcohol or fermented beverage called "tuba" or "soom" in the Philippines, "arak" or "tuak" in Indonesia, "toddy" in Malaysia, India and Bangladesh (Hamilton and Murphy, 1988; Päiväke, 1996). In this study, NFS was dehydrated to obtain the concentrated form and directly incorporated into the cake formulation by replacing it with white sugar in the cake. The microstructure characteristics of the carrot cake and how the structures and also other factors could affect the glycaemic index (GI) of the food of interest were investigated in this study.
The GI is a classification of carbohydrate foods based on their acute blood glucose responses. GI is defined as the incremental area under the blood glucose response curve (AUC) after consumption of a $50 \mathrm{~g}$ available-carbohydrate portion of a test food expressed as a percentage of the response to the same amount of carbohydrate from a reference food, normally glucose or white bread, consumed by the same subject. It is a measure of how high and how fast the blood glucose rises, and how effective the body responds by bringing it back to normal after ingestion of food (Whitney et al., 1990). According to the Food and Agriculture Organization [FAO] (1998), GI can be determined by collecting blood samples over $2 \mathrm{hrs}$ and calculating incremental AUC (iUAC; Jenkins et al., 1981). A diet with low GI is preferred in diabetic patients, as regulation of glycemia is primordial.

According to the Malaysian Adult Nutrition Survey (MANS), consumption of bakery products such as biscuits, bread, kuih has appeared in the list of the top ten daily consumed foods (Norimah et al., 2008). Therefore, being a popular, easily available and 
convenient food, bakery products have a wide potential in developing functional foods by incorporation or partial replacement for sweetener to improve the overall nutritional quality of the bakery products.

The main types of added sugar that are frequently used in processed foods are white refined sugars which are virtually $100 \%$ sucrose without additional nutrients (Insel et al., 2018). The GI of sucrose is 68, lower than the GI value of glucose $(\mathrm{GI}=100)$ but higher than the GI of fructose $(\mathrm{GI}=12)$. Fructose produces a lower blood glucose response because once fructose is absorbed by the gut, fructose would be metabolised in the liver into glycogen rather than be released in circulation and therefore resulted in a slower correction of blood glucose (Sun and Empie, 2012). Sucrose, on the other hand, is made up of monosaccharides, glucose and fructose and it has a medium GI between the GI value of glucose and fructose.

In this study, plain carrot cake was chosen as a baked-based product model for its healthier content. Partially substitution of the table sugar for concentrated $N$. fruticans sap (CNFS) up to $20 \%$ as a reduction of $20 \%$ sugar is the most acceptable and could be achieved without difficulty as reported by Shukla (1995). According to a previous study by Tai et al. (2019), it was found that there is an improvement in the carrot cake incorporated with $20 \%$ CNFS in terms of nutritional compositions and antioxidative properties due to the different sugar content (sucrose, fructose and glucose) in CNFS compared to table sugar which is pure sucrose. Besides it was also found that the $20 \%$ CNFSincorporated carrot cake received the highest sensory mean score for colour, appearance, texture and overall acceptance compared to the carrot cake without the addition of CNFS (control). Therefore, the control carrot cake and 20\% CNFS-incorporated carrot cake will be used in this study to compare the microstructure characteristics using scanning electron microscopy and also to determine their glycaemic index value.

\section{Materials and methods}

\subsection{Collection of Nypa fruticans sap}

Fresh $N$. fruticans sample (NFS) was collected and supplied from Pak Su Kemumin Enterprise, Kampung Kemumin, Kota Bharu, Kelantan state of Malaysia. The sap was acquired by cutting the stalk of matured nipa fruit and sap was collected four times daily to avoid spontaneous fermentation by minimising the chance of contamination through direct contact with the environment. The end cut of the stalk was wrapped with sterile plastic bags to maintain hygiene. The process of fermentation is reported to be rapid under sunlight.
Therefore, NFS was collected before sunrise and pooled together, and immediately delivered in a cooler box with ice at $-4^{\circ} \mathrm{C}$ to the laboratory located at the School of Health Sciences, Universiti Sains Malaysia, Kelantan. Fresh NFS was then filtered using a centrifugal seperator (Motor Sich-100-18 Separator, Ukraine) to remove the sedimentation. The batch for NFS collection used for further analysis in this study could be referred to Tai et al. (2019). Immediately, the quality of the fresh NFS sample was monitored prior to analysis by measuring its pH using HANNA pH 211 microprocessor $\mathrm{pH}$ meter (USA) according to the Association of Official Analytical Chemists [AOAC] (2012). If a fresh NFS sample has an initial $\mathrm{pH}$ below 4.0, the fresh NFS will be discarded as fermentation has possibly occurred in the sample.

\subsection{Processing of Nypa fruticans sap}

The dehydration technique and storage of NFS was done by using the method described by Tai et al. (2019). As soon as the fresh NFS arrived, forty grams of the filtered sap were dehydrated in a thermal dehydrator (Anywin FD770, China) at $62^{\circ} \mathrm{C}$ for an overnight (15 hrs) to evaporate the moisture content. After heated, CNFS samples obtained in the liquid syrup form were stored in a chiller at $4^{\circ} \mathrm{C}$ prior to analysis and further use.

\subsection{Preparation of carrot cakes}

Formulations of plain carrot cake for this study were adapted from a well-known baking site (Jaworski, 2019) with modification and listed in Table 1. CNFS syrup (g) was incorporated into the formulation to substitute sugar by $20 \%$ based on sugar weight $(\mathrm{g})$ as in the control formulation $(0 \%)$. To begin with, the dry ingredients: wheat flour, ground cinnamon, baking powder, baking soda were filtered and mixed evenly. In another bowl that contained the dry ingredients, eggs were mixed

Table 1. The raw ingredients used and incorporation level (\%) of CNFS

\begin{tabular}{|c|c|c|}
\hline \multirow[t]{2}{*}{ Ingredients (g) } & \multicolumn{2}{|c|}{$\begin{array}{c}\text { Formulation }(\% \text { CNFS used to replace } \\
\text { sugar) } g / 100 \mathrm{~g} \text { flour }\end{array}$} \\
\hline & $0 \%$ CNFS (control) & $20 \% \mathrm{CNFS}$ \\
\hline Sugar & 80.0 & 64.0 \\
\hline CNFS & 0.0 & 16.0 \\
\hline Wheat flour & 100.0 & 100.0 \\
\hline Corn oil & 50.0 & 50.0 \\
\hline Egg & 60.0 & 60.0 \\
\hline Ground cinnamon & 2.1 & 2.1 \\
\hline Baking powder & 4.2 & 4.2 \\
\hline Baking soda & 2.1 & 2.1 \\
\hline Carrot & 150.0 & 150.0 \\
\hline Orange zest & 1.0 & 1.0 \\
\hline Vanilla essence & 2.1 & 2.1 \\
\hline
\end{tabular}


together with the sugar or CNFS at speed 3 using an electric hand mixer (KHIND HM 200, Malaysia) for approximately 5 mins until the mixture turned pale and foamy. Next, corn oil was added into the egg mixture together with vanilla essence. Mixing was continued until the mixture was uniformly mixed. Next, the dry ingredients were added into the mixture by gently folding the former into the latter using a spatula. The grated carrot was then added to the mixture. The combined batter was poured into a 6-inch pan. The cake was baked at $150^{\circ} \mathrm{C}$ for 40 mins in the oven (ELBA 30L, Italy).

\subsection{Morphological characterization of carrot cakes using Scanning Electron Microscopy (SEM)}

The morphology of the starch granules of two formulations of carrot cake (control and 20\% NFSincorporated carrot cake), which were chosen based on sensory evaluation score obtained by Tai et al. (2019), was viewed by using an SEM (Brand: Fei, Model: Quanta FEG 450, Netherland). The cake samples were cut into small pieces with a blade to create a clean fracture surface. Samples were mounted on an aluminium sample holder and sputter-coated with a thin layer of gold in a vacuum evaporator (Baltex SCD005 Sputter Coater, Hi-Tech Germany) and placed in the SEM chamber for investigation. The microstructure of the samples with the magnification of $50 \times$ and $100 \times$ was photographed using a $5 \mathrm{kV}$ of electron beam-accelerating voltage and the diameter of the starch granules was measured.

\subsection{Glycaemic index determination}

The standard guidelines of GI determination suggested by Brouns et al. (2015) were followed. Fourteen non-diabetic, healthy volunteers were randomly selected from the School of Health Sciences, Universiti Sains Malaysia. The inclusion criteria were: age between 18 to 40 years, BMI of 18.1 to $24.9 \mathrm{~kg} / \mathrm{m}^{2}$, non-pregnant, non-lactating, non-smoker, carrying no history of acute or chronic illnesses and did not experience any surgical procedures during the past 6 months. After collecting a written informed consent form, a clinical examination was performed by a physician. Ethical approval for this study was acquired from the Human Research Ethics Committee (JEPeM) of Universiti Sains Malaysia (USM/ JEPeM/18070302).

Each subject conducts one trial of each test food and 3 trials of the reference food. The reference food trials are done at the beginning, middle and end of the series of tests, with the order of the test foods randomised between the reference foods. The reference food used in this study was glucose. It was prepared by dissolving 25 $\mathrm{g}$ of original flavoured Glucolin (Reckitt Benckiser, Malaysia) in $250 \mathrm{~mL}$ drinking water. The $25 \mathrm{~g}$ Glucolin contains $25 \mathrm{~g}$ available carbohydrate (dextrose monohydrate). Participants were served with $25 \mathrm{~g}$ available carbohydrate portions of the control food $(0 \%$ CNFS carrot cake) and the test food (20\% CNFS carrot cake) to avoid unrealistically oversized serving. A standard drink of $250 \mathrm{~mL}$ water was served with each test food. During each session, fingertip capillary blood samples were collected at fasting and further blood samples were collected at 15,30, 45, 60, 90 and 120 mins after participants consume the test food. When the blood drop is large enough, it was collected from the punctured skin into the cavity of disposable microcuvette (HemoCue Glucose 201 RT Microcuvette, Sweden) by capillary action. After inserted into the glucometer (HemoCue Glucose 201 RT, Sweden), the glucose value of the blood sample is displayed in $\mathrm{mmol} / \mathrm{L}$.

The incremental area under the curve (iAUC) was calculated using Microsoft Excel (Version 365 ProPlus, USA), in which the trapezoid rule was applied. If the blood glucose response falls below the baseline, only the area above the fasting level was included. The calculation of GI was done by applying the equation below (FAO/WHO, 1998).

$$
\mathrm{GI}=\frac{\text { Area under the glucose curve of test food }}{\text { Area under glucose curve of reference food }} \times 100
$$

The GI of each test food is expressed as the percentage of iAUC for the test food over the mean iAUC for glucose consumed by the same participant. The resulting values for all participants were averaged to calculate the GI for each test food.

\subsection{Statistical analysis}

The results were analysed using IBM SPSS Statistics Version 19. Data were presented as mean values of fourteen replicates \pm standard error mean (SEM) for iAUC and glycaemic index determination which were subjected to one-way ANOVA. For comparison of means, Tukey HSD was used and a significant difference was determined at $\mathrm{p}<0.05$.

\section{Results}

\subsection{Microstructure characteristics}

Figure 1(A) and 1(B) represent the micrograph of crumb of the control $(0 \%)$ and $20 \%$ CNFS-incorporated carrot cakes. As seen at the same magnification level, the microstructure of both carrot cakes greatly differed if compared. The control carrot cake crumb (Figure 1A) contained more rough and irregular particles than the oval-shaped particles, as shown in the carrot cake crumb incorporated with a 20\% level of CNFS (Figure 1B). 

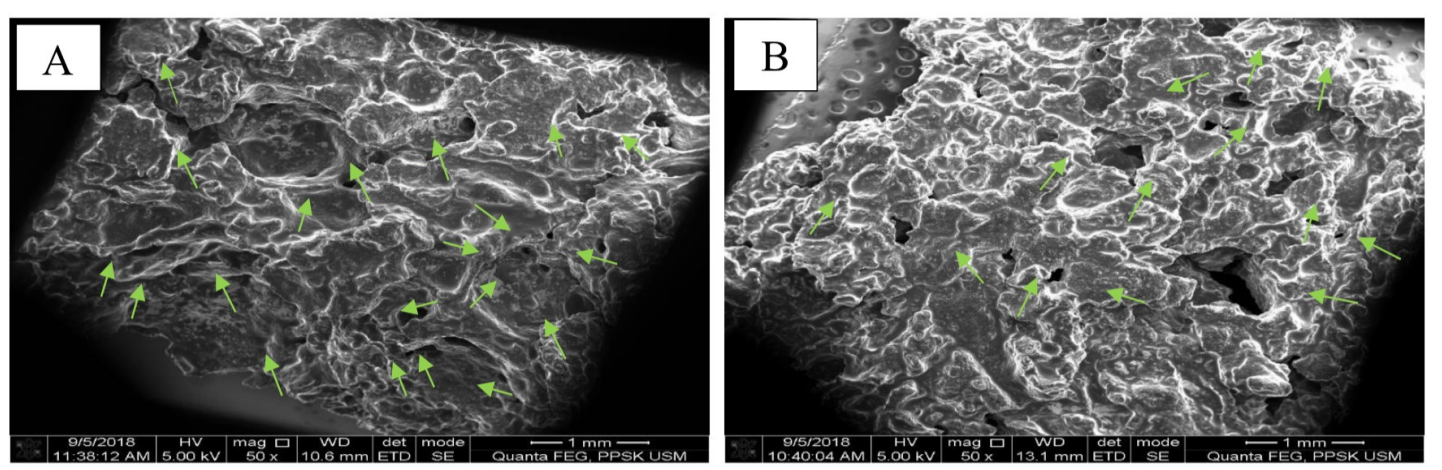

Figure 1. Scanning electron micrographs (50×) of carrot cake. (A) control carrot cake; (B) 20\% CNFS carrot cake. Green arrow represents open structure of carrot cake crumb.
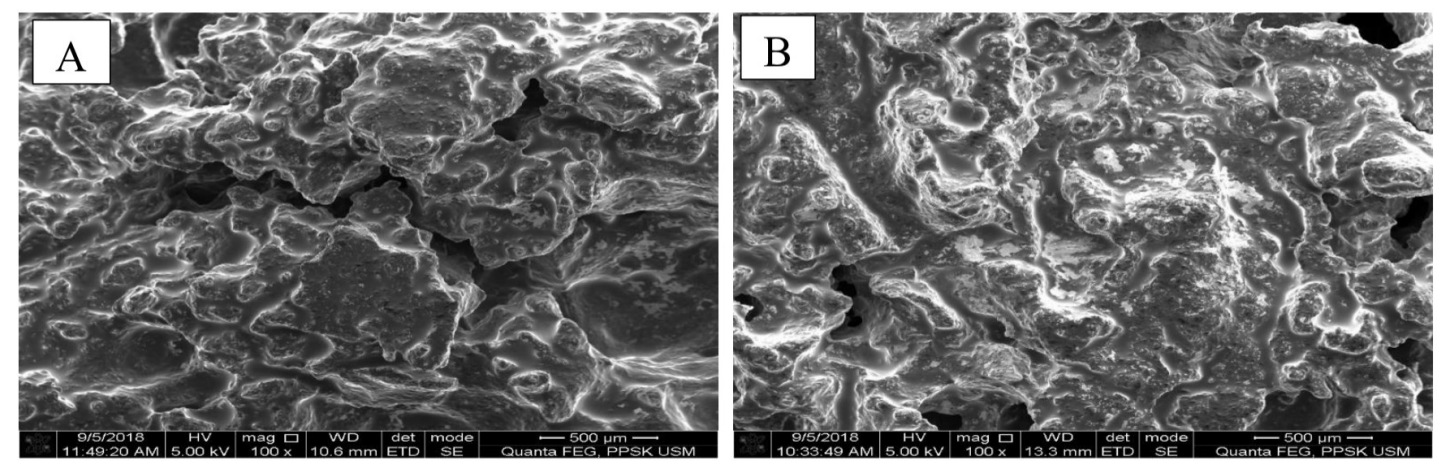

Figure 2. Scanning electron micrograph (100×) of carrot cake. (A) control carrot cake; (B) 20\% CNFS carrot cake.

Besides based on Figure 2(B), the carrot cake crumbs incorporated with $20 \%$ CNFS were also shown to have a more homogenous, dense or compact structure compared to the crumbs of the control carrot cake based on Figure 2(A) which had a more irregular and loose structure.

Based on Figure 1(A) and 1(B), the SEM micrograph illustrated that the replacement of sugar with CNFS has directly reduced the number of air cells presented in the carrot cake crumb. By calculating the number of air cells represented by the open structure of the cake crumbs in SEM micrograph from Figure 1(A) and 1(B), the control carrot cake (Figure 1A) was found to have about 20 air cells in the carrot cake crumb which was higher as compared with the carrot cake incorporated with $20 \%$ CNFS (Figure 1B) with only about 13 air cells presented. Figure 2(A) and 2(B) shows a closer look at the open structure of the carrot cake crumb.

\section{2 iAUC and GI value determination}

The calculation of glucose response (iAUC) for each food and participants allows the evaluation of GI of the test foods. The iAUC and GI values are shown in Table 2. According to Dona et al. (2010), carbohydrate foods can be classified into three categories based on their GI values: The high GI foods $(>70)$, intermediate GI foods $(>55-<70)$ and low GI foods $(<55)$ on the basis of a GI for glucose drink is 100. Based on the result, the GI values of both carrot cakes incorporated with $0 \%$ (control) and 20\% CNFS were classified as a low GI. However, there was a significant difference $(\mathrm{p}<0.05)$ between the control cake ( $0 \%$ CNFS) and 20\% CNFS carrot cake. The $0 \%$ NFS cake with the GI value of 55 is significantly $(p<0.05)$ higher than the $20 \%$ NFS cake with the GI value of 50 .

Table 2. Glucose response (iAUC) and GI values of test foods

\begin{tabular}{ccc}
\hline Test Food & iAUC & GI \\
\hline Glucose (reference) & $207 \pm 10^{\mathrm{a}}$ & $100^{\mathrm{a}}$ \\
$0 \%$ CNFS carrot cake (control) & $111 \pm 9^{\mathrm{b}}$ & $55 \pm 2^{\mathrm{b}}$ \\
$20 \%$ CNFS carrot cake & $101 \pm 9^{\mathrm{b}}$ & $50 \pm 2^{\mathrm{c}}$ \\
\hline
\end{tabular}

Values are expressed as mean \pm SEM $(n=14)$. Values with the same superscript within the same column are not significantly different $(\mathrm{p}>0.05)$.

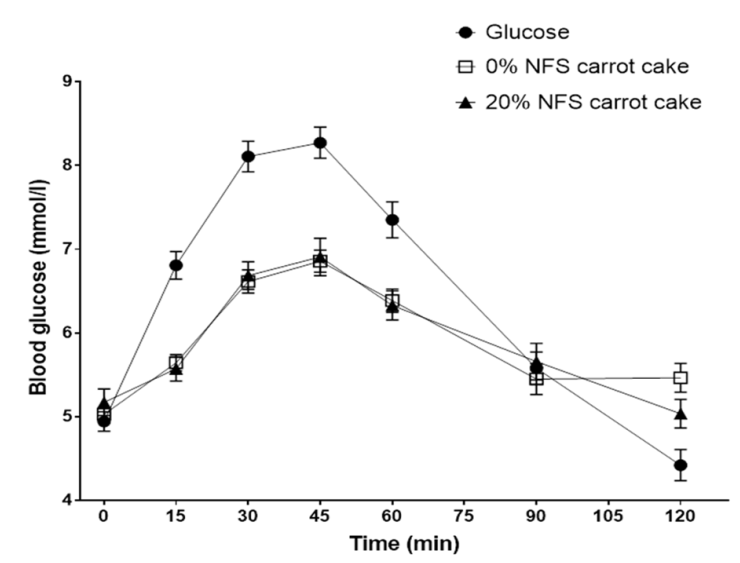

Figure 3. Mean blood glucose responses to $0 \%$ CNFS carrot cake compared with $20 \%$ CNFS carrot cake

The iAUC for glucose was the highest and the $0 \%$ CNFS cake being the second-highest and followed by the $20 \%$ CNFS carrot cake. There was no significant difference $(p>0.05)$ noted between the glycaemic response represented by iAUC of the control cake $(0 \%$ 
CNFS) and the 20\% CNFS carrot cake. However, both $0 \%$ and $20 \%$ CNFS carrot cake had obtained a significantly lower value of glycaemic response than the reference glucose (Figure 3).

\section{Discussion}

The microstructure and quality of the cakes are highly influenced by the foaming properties of the egg. Therefore, the preparation of foam is regarded as the most important step in cake preparation. In the present study, the preparation of foam was done using the meringue technique to incorporate air bubbles into carrot cakes. The presence of sugar (sucrose) plays an important role at this stage in stabilising the foam structure (Sozer et al., 2011). This statement was supported by Yang and Foegeding (2009) which found that cakes with a higher level of sugar concentration produced cakes with larger air cells which are more stable. The previous findings are in line with the carrot cakes produced in this study. Based on the microstructure characteristics of the control and $20 \%$ CNFS-incorporated carrot cake, it could be seen that the structure of the control carrot cake contained more rough and irregular particles than the cake incorporated with CNFS. Besides, a greater number of air cells in the control cake than the 20\% CNFS-incorporated carrot cakes could also be observed from the SEM results. One of the explanations for the different structure of both carrot cakes might be related to the sugar content used in the formulations of this study. As mentioned earlier, the presence of sucrose takes a part in stabilising the foam and eventually the structure of the carrot cakes after baking. The sugar used in the control cake contained purely sucrose without other content whereas the CNFS used to replace sugar in the CNFS-incorporated carrot cake was analysed earlier and found not only made up of sucrose but also fructose and glucose. (Insel et al., 2018; Tai et al., 2019). This might explain the dense, compact and also a lesser number of air cells structure as can be seen in 20\% CNFS-incorporated carrot cake.

There are various factors of foods that affect GI include gross and cellular structures, nature of starch, type of sugar, organic acid and dietary fibre contents (Arvidsson-Lener et al., 2004). In the present study, we purported that the food structure might have influenced the glycaemic responses of the carrot cake. In starchy foods, the food or substrate structure and arrangement could affect the enzyme availability of the carbohydrate moiety and thus affecting the metabolic responses to the foods and hence the glycaemic index. Based on the results from the SEM micrograph, the crumb of carrot cake incorporated with $20 \%$ CNFS was shown to have a more homogenous and dense starch granule structure as compared with the control carrot cake which had a loose and irregular granule distribution. This finding suggested that carrot cake incorporated with CNFS with a more compact structure could reduce the accessibility of carbohydrate digestion enzyme such as $\alpha$-amylase to act on the starch granules, delaying the digestion process and as a result a lower postprandial glucose response (Raben et al., 1997). Besides, from the SEM result, our study also found that the carrot cake incorporated with CNFS had a lesser number of air cells than the cake without CNFS. This again suggested that the incorporation of CNFS also reduced the high porosity caused by the entrapment of gas bubbles that expand during baking which decreased the surface exposed to enzyme activity. The low porosity in leavened foods indirectly reduced the rate of starch accessibility owing to a combination of compact form and the need for protein digestion to free trapped starch granules (Riccardi et al., 2003).

\section{Conclusion}

The microstructure characteristics of the carrot cakes added with concentrated $N$. fruticans sap are affected in which the cake added with the sap contains a denser, and compact starch granule structure compared to the carrot cake without the addition of the sap. Besides, a lesser number of air cells was also observed in carrot cake incorporated with $20 \%$ CNFS. The food structure has directly contributed to the lower rise in postprandial blood glucose responses and hence a lower glycaemic index value. Cake developed from carrot and CNFS could both be classified as low GI food. The addition of CNFS in carrot cake has led to a lower GI value $(\mathrm{GI}=50)$ than the control cake without the addition of CNFS $(\mathrm{GI}=55)$. Using carrot cake as a bakery product model, the present findings suggested that novel ingredient like CNFS could be used as an alternative to replacing sugar in processed foods to achieve a lower GI value. For future study, the incorporation of CNFS in other bakery products such as bread, cookies, pastries and biscuits as a study and product shelf-life model is also proposed.

\section{Conflict of interest}

The authors declare no conflict of interest.

\section{Acknowledgments}

The authors acknowledge Bridging-Incentive Grant by Universiti Sains Malaysia (Grant no: 304/ PPSK/6316333) and USM Fellowship Scheme for providing financial assistance. Special thanks to the contributions from the staff members of the food preparation lab and nutrition lab in the School of Health Sciences, Universiti Sains Malaysia for completing this 
study.

\section{References}

Aimi, R.N., Bakar, A.F. and Dzulkifly, M.H. (2013). Determination of volatile compounds in fresh and fermented nipa sap (Nypa fruticans) using static headspace gas chromatography-mass spectrometry (GC-MS). International Food Research Journal, 20 (1), 369-376.

Arvidsson-Lenner, R., Asp, N.G., Axelsen, M., Bryngelsson, S., Haapa, E., Järvi, A., Karlström, B., Raben, A., Sohlström, A., Thordottir, I. and Vessby, B. (2004). Glycaemic index: Relevance for health, dietary recommendations and food labelling. Scandinavian Journal of Nutrition, 48(2), 84-94. https://doi.org/10.1080/11026480410033999

Brouns, F., Bjorck, I., Frayn, K., Gibbs, A., Lang, V., Slama, G. and Wolever, T.M. (2005). Glycemic index methodology. Nutrition Research Reviews, 18 (1), 145-171. https://doi.org/10.1079/NRR2005100

Dona, A.C., Pages, G., Gilbert, R.G. and Kuchel, P.W. (2010). Digestion of starch: In vivo and in vitro kinetic models used to characterise oligosaccharide or glucose release. Carbohydrate Polymers, 80(3), 599-617.

j.carbpol.2010.01.002

https://doi.org/10.1016/

FAO/WHO. (1998). Carbohydrates in Human Nutrition: Report of a Joint FAO/WHO Expert Consultation, 1997. FAO Food and Nutrition Paper No. 66. Rome: FAO.

Fong, F.W. (1992). Perspective for sustainable resource utilization and management of nipa vegetation. Economic Botany, 46(1), 45-54. https:// doi.org/10.1007/BF02985253

Hamilton, L.S. and Murphy, D.H. (1988). Use and management of nipa palm (Nypa fruticans, Arecaceae): A review. Economic Botany, 42(2), 206213. https://doi.org/10.1007/BF02858921

Insel, P., Ross, D., McMahon, K. and Bernstein, M. (2018). Discovering nutrition. Burlington, USA: Jones and Bartlett Learning.

Jaworski, S. (2019). Carrot cake recipe and video. Retrieved on January 13, 2019 from https:// www.joyofbaking.com/CarrotCake.html

Jenkins, D.J., Wolever, T.M., Taylor, R.H., Barker, H., Fielden, H., Baldwin, J.M., Bowling, A.C., Newman, H. C., Jenkins, A.L. and Goff, D.V. (1981). Glycemic index of foods: a physiological basis for carbohydrate exchange. The American Journal of Clinical Nutrition, 34(3), 362-366. https:// doi.org/10.1093/ajen/34.3.362

Nguyen, D.V., Rabemanolontsoa, H. and Saka, S.
(2016). Sap from various palms as a renewable energy source for bioethanol production. Chemical Industry and Chemical Engineering Quarterly, 22 (4), 355-373. https://doi.org/10.2298/ CICEQ160420024N

Norimah, A.K., Safiah, M., Jamal, K., Haslinda, S., Zuhaida, H., Rohida, S., Fatimah, S., Norazlin, S., Poh, B.K., Kandiah, M., Alilah, M.S., Manan, W.W.M., Fatimah, S. and Azmi, M.Y. (2008). Food consumption patterns: findings from the Malaysian adult nutrition survey (MANS). Malaysian Journal of Nutrition, 14(1), 25-39.

Päiväke, A.E.A. (1996). Plant yielding non-seed carbohydrate. In Flach, M. and Rumawas (Eds). Plant resource of South-East Asia. Bogor, Indonesia: Prosea Foundation.

Riccardi, G., Clemente, G. and Giacco, R. (2003). Glycemic index of local foods and diets: the mediterranean experience. Nutrition Reviews, 61(5), 56-60. https://doi.org/10.1301/nr.2003.may.S56-S60

Sozer, N., Bruins, R., Dietzel, C., Franke, W. and Kokini, J. (2011). Improvement of shelf life stability of cakes. Journal of Food Quality, 34(3), 151-162. https://doi.org/10.1111/j.1745-4557.2011.00379.x

Sun, S.Z. and Empie, M.W. (2013). Fructose metabolism in humans: What isotopic tracer studies tell us. Functional Foods: The Connection Between Nutrition, Health, and Food Science, 9, 89.

Tai, Y.Y., Alina, T.I.T. and Wan Rosli, W.I. (2019). Improvement of physico-chemical properties, antioxidant capacity and acceptability of carrot cake by partially substituting sugar with concentrated Nypa fruticans sap. Pertanika Journal of Tropical Agricultural Sciences, 42(3), 1-20.

Whitney, E.N., Hamilton, E.M.N. and Rofles, S.R. (1990). Understanding Nutrition. 5th ed. New York, USA: West Publishing.

Yang, X. and Foegeding, E.A. (2010). Effects of sucrose on egg white protein and whey protein isolate foams: Factors determining properties of wet and dry foams (cakes). Food Hydrocolloids, 24(2), 227-238. https:// doi.org/10.1016/j.foodhyd.2009.09.011 